\title{
Blood glucose levels within 7 days after birth in preterm infants according to gestational age
}

\author{
Ju Young Yoon, MD', \\ Hye Rim Chung, MD, PhD², \\ Chang Won Choi, MD, $\mathrm{PhD}^{2}$, \\ Sei Won Yang, MD, PhD', \\ Beyong II Kim, MD, PhD², \\ Choong Ho Shin, MD, PhD ${ }^{1}$
}

${ }^{1}$ Department of Pediatrics, Seoul National University Children's Hospital, Seoul, ${ }^{2}$ Department of Pediatrics, Seoul National University Bundang Hospital, Seongnam, Korea

\author{
Received: 23 November, 2015 \\ Revised: 4 December, 2015 \\ Accepted: 14 December, 2015 \\ Address for correspondence: \\ Hye Rim Chung, MD, PhD \\ Department of Pediatrics, Seoul \\ National University Bundang \\ Hospital, 82 Gumi-ro 173beon-gil, \\ Bundang-gu, Seongnam 13620, \\ Korea \\ Tel: +82-31-787-2034 \\ Fax: +82-31-787-4054 \\ E-mail: chyerim@hanmail.net
}

Purpose: This study investigated blood glucose levels in preterm babies according to gestational age (GA).

Methods: Subjects were 141 preterm infants with a GA<34 weeks. Data on blood glucose levels, GA, body weight, glucose infusion rate, and other contributing factors in the first 7 days after birth were analyzed. Hypoglycemia was defined as a blood glucose level of $<40 \mathrm{mg} / \mathrm{dL}$ up to 24 hours after birth and as $<50 \mathrm{mg} / \mathrm{dL}$ thereafter. Hyperglycemia was defined as a blood glucose level $>180 \mathrm{mg} / \mathrm{dL}$.

Results: During the 7 days after birth, hypo- and hyperglycemia occurred in 29 (29 of $141,20.6 \%$ ) and 42 (42 of $141,29.8 \%$ ) neonates, respectively. During the first 2 hours, 18 neonates (12.8\%) exhibited hypoglycemia, and only 2 ( 2 of $141,1.4 \%$ ) developed hyperglycemia. From 6 to 24 hours, hypo- and hyperglycemia were observed in 0 and 9 (9 of 141, 6.4\%) neonates, respectively. Infants small for their GA (SGA) were at risk for hypoglycemia both within 24 hours (odds ratio [OR], 2.718; $P=0.045)$ and during days 2 to $7(\mathrm{OR}, 4.454 ; P=0.006)$, and hyperglycemia during days 2 to 7 (OR, 3.200; $P=0.005)$. Low 1-minite Apgar score was risk factor for both hypo- and hyperglycemia during days 2 to 7 (OR, 0.756; $P=0.035$ for hypoglycemia and $\mathrm{OR}, 0.789 ; P=0.016$ for hyperglycemia). Both hypo- and hyperglycemia within 24 hours were less common in those who started feeding (OR, 0.294; $P=0.013$ for hypoglycemia and OR, $0.162 ; P=0.011$ for hyperglycemia).

Conclusion: Careful blood glucose level monitoring is required in preterm infants, especially SGA infants or those with low Apgar score. Early feeding could be beneficial for maintaining euglycemia.

Keywords: Blood glucose level, Preterm, Birth weight, Gestational age

\section{Introduction}

Preterm infants have limited supplies and stores of energy sources for carbohydrate metabolism. In addition, the organs involved in the regulation of energy metabolism, which include the liver, pancreas, brain, and endocrine organs, are immature ${ }^{1)}$. Therefore, hypo- and hyperglycemia are more common in preterm infants than in full-term neonates. Hypoglycemia is also common in infants who are small for gestational age (SGA) $)^{2)}$, as well as in those with perinatal asphyxia ${ }^{3)}$. Hyperglycemia occurs more frequently under conditions of excess glucose and lipid infusion, as well as under stressful conditions such as mechanical ventilation and hypoxia.

Persistent and recurrent hypoglycemia in neonates is associated with long-term neurological complications such as visual defects ${ }^{4)}$, localization-related epilepsy ${ }^{5-7)}$, and cognitive dysfunction $^{8-10)}$. Complications of hyperglycemia include intraventricular hemorrhage, premature retinopathy, and bronchopulmonary dysplasia ${ }^{11)}$.

However, little is known about prevalence of hypo- or hyperglycemia in preterm infants, resulting in challenges for prevention and management. The present study aimed to provide 
useful data for the prevention and treatment of hypo- or hyperglycemia in preterm infants by investigating blood glucose levels for a period of 7 days after birth, as well as the prevalence of and risk factors for these conditions.

\section{Materials and methods}

\section{Subjects}

Preterm infants born at a gestational age (GA) of $<34$ weeks at Seoul National University Bundang Hospital, Korea, were enrolled in this study. Of the 156 preterm infants born at a GA of $<34$ weeks between March 2010 and December 2011, 15 were excluded from the study (due to death within 7 days of birth $[n=8]$ or maternal diabetes mellitus [ $n=7]$ ). Finally, a total of 141 infants were enrolled in this study.

\section{Methods}

Blood glucose levels were measured irrespective of feeding time at least twice a day for the first 3 days after birth and at least once a day from days 4 to 7 . Whole blood samples were obtained from the heel using the OneTouch SureStep Hospital Meter (LifeScan Inc., Milpitas, CA, USA). Because there is no consensus about definition of hypo and hyperglycemia, we used our target blood glucose level for cutoff value. Hypoglycemia was defined as a blood glucose measurement $<2.22 \mathrm{mmol} / \mathrm{L}$ ( 40 $\mathrm{mg} / \mathrm{dL}$ ) within 24 hours of birth and $<2.78 \mathrm{mmol} / \mathrm{L}(50 \mathrm{mg} /$ dL) thereafter. Hyperglycemia was defined as a blood glucose measurement $>9.99 \mathrm{mmol} / \mathrm{L}(180 \mathrm{mg} / \mathrm{dL})$ regardless of the sampling time.

Patients were infused with a glucose-containing fluid at an initial glucose infusion rate (GIR) of $4 \mathrm{mg} / \mathrm{kg} / \mathrm{min}$. The GIR was titrated by 0.5 to $1 \mathrm{mg} / \mathrm{kg} / \mathrm{min}$ daily up to 12 to $15 \mathrm{mg} / \mathrm{kg} /$ min, to maintain blood glucose levels within target range of

Table 1. Characteristics of the patients and mothers according to gestational age group

\begin{tabular}{|c|c|c|c|c|c|}
\hline Characteristic & Overall $(n=141)$ & $\mathrm{GA}(w \mathrm{w})<28(\mathrm{n}=21)$ & $28 \leq G A(w k)<30(n=15)$ & $30 \leq \mathrm{GA}(w \mathrm{k})<32(\mathrm{n}=39)$ & $32 \leq \mathrm{GA}(w k)<34(n=66)$ \\
\hline Birthweight (kg) & $1.53 \pm 0.56$ & $0.80 \pm 0.21$ & $1.02 \pm 0.29$ & $1.44 \pm 3.43$ & $1.94 \pm 0.42$ \\
\hline $\mathrm{GA}(w k)$ & $31.0 \pm 2.6$ & $26.2 \pm 1.3$ & $28.7 \pm 0.4$ & $31.0 \pm 0.5$ & $33.1 \pm 0.6$ \\
\hline Male sex & $81(57.4)$ & $13(61.9)$ & $11(73.3)$ & $18(46.2)$ & $39(59.1)$ \\
\hline Multiple pregnancy & $30(21.3)$ & $4(19.0)$ & $4(26.7)$ & $8(20.5)$ & $14(21.2)$ \\
\hline Vaginal delivery & 45 (31.9) & $8(38.1)$ & $4(26.7)$ & $7(17.9)$ & $26(39.4)$ \\
\hline SGA & $37(26.2)$ & $6(28.6)$ & $7(46.7)$ & $10(25.6)$ & $14(21.2)$ \\
\hline Breast milk feeding & $72(55.0)$ & $6(28.6)$ & $8(57.1)$ & $27(75.0)$ & $31(47.0)$ \\
\hline Feeding start within 24 hours ${ }^{\mathrm{a})}$ & $98(69.5)$ & $8(38.1)$ & $6(40.0)$ & $23(59.0)$ & $61(92.4)$ \\
\hline Full feeding within 7 days ${ }^{\mathrm{a}, \mathrm{b})}$ & $137(97.2)$ & $21(100)$ & $15(100)$ & $37(94.9)$ & $64(97.0)$ \\
\hline Time to full feeding (day) & $3.9 \pm 1.3$ & $4.9 \pm 1.5$ & $4.7 \pm 1.5$ & $3.8 \pm 1.1$ & $3.5 \pm 1.0$ \\
\hline Initial blood glucose (mmol/L) & $3.9 \pm 1.4$ & $4.8 \pm 2.1$ & $3.5 \pm 0.9$ & $3.4 \pm 1.3$ & $3.9 \pm 1.3$ \\
\hline \multicolumn{6}{|l|}{$\mathrm{GIR}(\mathrm{mg} / \mathrm{kg} / \mathrm{min})$} \\
\hline Day 1 & $3.9 \pm 0.7$ & $3.9 \pm 0.7$ & $4.1 \pm 0.9$ & $3.9 \pm 0.9$ & $4.0 \pm 0.7$ \\
\hline Days 2-7 & $4.5 \pm 2.4$ & $6.0 \pm 1.1$ & $6.3 \pm 1.9$ & $4.7 \pm 2.4$ & $3.4 \pm 2.3$ \\
\hline Peak GIR (mg/kg/min) & $6.4 \pm 2.2$ & $7.3 \pm 1.5$ & $8.0 \pm 2.3$ & $6.6 \pm 2.4$ & $5.7 \pm 2.0$ \\
\hline \multicolumn{6}{|l|}{ Hypoglycemia } \\
\hline$<24$ hours & $20(14.2)$ & $2(9.5)$ & $3(20.0)$ & $8(20.5)$ & $7(10.6)$ \\
\hline Days 2-7 & $16(11.3)$ & $4(19)$ & $2(13.3)$ & $7(17.9)$ & $3(4.5)$ \\
\hline \multicolumn{6}{|l|}{ Hyperglycemia } \\
\hline$<24$ hours & $10(7.1)$ & $4(19)$ & $1(6.7)$ & $2(5.1)$ & $3(4.5)$ \\
\hline Days $2-7^{*}$ & $36(25.5)$ & $16(76.2)$ & $5(33.3)$ & $9(23.1)$ & $6(9.1)$ \\
\hline \multicolumn{6}{|l|}{ Apgar score } \\
\hline 1 minute & $5.0 \pm 2.0$ & $3.0 \pm 1.8$ & $4.9 \pm 2.4$ & $4.6 \pm 1.6$ & $5.8 \pm 1.7$ \\
\hline 5 minutes & $6.9 \pm 1.7$ & $5.1 \pm 1.9$ & $6.8 \pm 1.9$ & $6.7 \pm 1.3$ & $7.6 \pm 1.3$ \\
\hline RDS & $56(39.7)$ & $19(90.5)$ & $8(53.3)$ & $18(46.2)$ & $11(16.7)$ \\
\hline Sepsis & $4(2.8)$ & $3(14.3)$ & $0(100)$ & $1(2.6)$ & $0(0)$ \\
\hline Free T4 (pmol/L) & $19.1 \pm 4.0$ & $15.2 \pm 4.1$ & $17.7 \pm 3.0$ & $19.3 \pm 3.6$ & $20.8 \pm 3.5$ \\
\hline 17-OHP (pmol/L) & $358 \pm 519$ & $846 \pm 1150$ & $310 \pm 205$ & $295 \pm 217$ & $250 \pm 210$ \\
\hline $\mathrm{PIH}$ & $31(22.0)$ & $3(14.3)$ & $5(33.3)$ & $9(23.1)$ & $14(21.2)$ \\
\hline Maternal steroid & $122(86.5)$ & $19(90.5)$ & $14(93.3)$ & $32(82.1)$ & $57(86.4)$ \\
\hline
\end{tabular}

Values are presented as mean \pm standard deviation or number (\%).

GA, gestational age; SGA, small for GA; GIR, glucose infusion rate; RDS, respiratory distress syndrome; 17-OHP, 17-hydroxyprogesterone; PIH, pregnancyinduced hypertension.

${ }^{*} P<0.05$ between groups. ${ }^{\text {a) }}$ Time from birth. ${ }^{\text {b) }}$ Full feeding: oral intake more than $100 \mathrm{~mL} / \mathrm{kg} /$ day. 
2.78-9.99 mmol/L (50-180 mg/dL). Hypo- and hyperglycemia were managed by adjusting glucose infusion rate. Feeding was initiated on the first day, if tolerable.

In addition to the measurement of blood glucose levels, sex, GA, birth weight, multiple pregnancies, method of delivery, prenatal steroid use, and maternal hypertension were recorded. We further collected information on perinatal factors associated with blood glucose levels, including GIR, feeding (breast milk or whole milk), and Apgar scores. In order to evaluate the hormonal status, free thyroxine (T4) and 17-hydroxyprogesterone (17-OHP) levels were measured on day 7 by serum radioimmunoassay and the neonatal screening test, respectively.

This study was approved by the Institutional Review Board of Seoul National University Bundang Hospital (IRB No. B-1203/148-101).

\section{Statistical analysis}

Results are expressed as the mean \pm standard deviation. Intergroup comparisons were conducted using independent $t$-tests or the chi-square test where appropriate. In addition, stepwise logistic regression analysis was performed to determine those factors influencing the occurrence of hypo- or hyperglycemia. These results are expressed as the odds ratios (ORs) with 95\% confidence intervals (CIs).

Analyses were performed using the IBM SPSS Statistics ver. 19.0 (IBM Co., Armonk, NY, USA). A $P$-value $<0.05$ was considered statistically significant.

\section{Results}

\section{Patient characteristics}

The mean birth weight of all subjects was $1.53 \pm 0.56 \mathrm{~kg}$. Of these, 37 infants $(26.2 \%)$ were classified as SGA.

The subjects were divided into 4 groups according to GA: $<28,28$ to $<30,30$ to $<32$, and $\geq 32$ weeks. No differences were observed between groups in terms of characteristics such as sex, multiple births, and method of delivery (vaginal vs. Cesarean section).

With regards to those perinatal factors that could affect blood glucose levels, as the group was younger, Apgar scores at 1 and 5 minutes were significantly lower, free T4 levels were lower, 17OHP levels were higher, and a greater proportion of subjects developed respiratory distress syndrome. Feeding method, GIR during day 1, and maternal factors such as maternal hypertension or steroid use were not significantly different between the 4 groups (Table 1 ).

We grouped the subjects according to presence of hypo- and

Table 2. Characteristics of the patients and mothers according to presence of hypo- and hyperglycemia

\begin{tabular}{|c|c|c|c|c|c|c|c|c|c|}
\hline \multirow{2}{*}{ Characteristic } & \multirow{2}{*}{$\begin{array}{l}\text { Overall } \\
(n=141)\end{array}$} & \multicolumn{4}{|c|}{ Hypoglycemia within 24 hours } & \multicolumn{4}{|c|}{ Hypoglycemia during days 2-7 } \\
\hline & & Yes $(n=20)$ & No $(n=121)$ & Yes $(n=16)$ & No $(n=125)$ & Yes $(n=10)$ & No $(n=131)$ & Yes $(n=36)$ & No $(n=105)$ \\
\hline Birthweight (kg) & $1.53 \pm 0.56$ & $1.54 \pm 0.68$ & $1.53 \pm 0.54$ & $1.13 \pm 0.48^{*}$ & $1.58 \pm 0.55$ & $1.28 \pm 0.74$ & $1.55 \pm 0.54$ & $1.06 \pm 0.56$ & $1.69 \pm 0.47$ \\
\hline $\mathrm{GA}(w k)$ & $31.0 \pm 2.6$ & $31.0 \pm 0.6$ & $31.0 \pm 2.6$ & $29.7 \pm 3.1^{*}$ & $31.2 \pm 2.5$ & $29.2 \pm 3.4$ & $31.2 \pm 2.5$ & $28.7 \pm 2.9$ & $31.8 \pm 1.8$ \\
\hline Male sex & $81(57.4)$ & $11(55)$ & $70(57.9)$ & $9(56.3)$ & $72(57.6)$ & $7(70.0)$ & $74(56.5)$ & $18(50.0)$ & $63(60.0)$ \\
\hline Multiple pregnancy & $30(21.3)$ & $7(35.0)$ & $23(19.0)$ & $2(12.5)$ & $28(22.4)$ & $1(10.0)$ & $29(22.1)$ & $7(19.4)$ & $23(21.9)$ \\
\hline Vaginal delivery & $45(31.9)$ & $3(15.0)$ & $42(34.7)$ & $3(18.8)$ & $42(33.6)$ & $0(0)$ & $45(34.4)$ & $8(22.2)$ & $37(35.2)$ \\
\hline SGA & $37(26.2)$ & $9(45.0)$ & $28(23.1)$ & $9(56.3)^{*}$ & $28(22.4)$ & $4(40.0)$ & $33(25.2)$ & $16(44.4)^{*}$ & $21(20 / 0)$ \\
\hline Breast milk feeding & $72(55.0)$ & $12(60.0)$ & $60(49.6)$ & $10(62.5)$ & $62(49.6)$ & $6(60.0)$ & $66(50.4)$ & $15(41.7)$ & $57(53.3)$ \\
\hline Feeding start within 24 hours ${ }^{\mathrm{a})}$ & $98(69.5)$ & $9(45.0)^{*}$ & 89 (73.6) & - & - & $3(30.0)^{*}$ & $95(72.5)$ & - & - \\
\hline Time to full feeding (day) ${ }^{b)}$ & $3.9 \pm 1.3$ & $4.0 \pm 1.1$ & $3.9 \pm 1.3$ & $3.9 \pm 1.0$ & $3.9 \pm 1.3$ & $4.3 \pm 1.5$ & $3.9 \pm 1.3$ & $4.3 \pm 1.5$ & $3.8 \pm 1.2$ \\
\hline Initial blood glucose (mmol/L) & $3.9 \pm 1.4$ & $2.3 \pm 1.2^{*}$ & $4.1 \pm 1.3$ & $3.3 \pm 1.8$ & $3.9 \pm 1.4$ & $4.2 \pm 1.4$ & $3.8 \pm 1.4$ & $4.1 \pm 1.7$ & $68.2 \pm 24.2$ \\
\hline \multicolumn{10}{|l|}{$\mathrm{GIR}(\mathrm{mg} / \mathrm{kg} / \mathrm{min})$} \\
\hline Day 1 & $3.9 \pm 0.7$ & $3.8 \pm 0.6$ & $4.0 \pm 0.8$ & $3.8 \pm 0.5$ & $4.0 \pm 0.8$ & $4.0 \pm 0.8$ & $3.9 \pm 0.7$ & $3.9 \pm 0.9$ & $3.9 \pm 0.7$ \\
\hline Days 2-7 & $4.5 \pm 2.4$ & $4.3 \pm 2.3$ & $4.5 \pm 2.4$ & $6.2 \pm 1.7^{*}$ & $4.3 \pm 2.4$ & $5.5 \pm 1.3$ & $4.4 \pm 2.4$ & $5.9 \pm 2.0$ & $4.0 \pm 2.3$ \\
\hline \multicolumn{10}{|l|}{ Apgar score } \\
\hline 1 minute & $5.0 \pm 2.0$ & $4.8 \pm 1.7$ & $5.0 \pm 2.1$ & $3.9 \pm 1.7^{*}$ & $5.1 \pm 2.0$ & $4.0 \pm 1.9$ & $5.0 \pm 2.0$ & $4.3 \pm 2.2$ & $5.2 \pm 1.9$ \\
\hline 5 minutes & $6.9 \pm 1.7$ & $6.9 \pm 1.7$ & $6.9 \pm 1.7$ & $5.9 \pm 1.5^{*}$ & $7.0 \pm 1.7$ & $5.9 \pm 1.6$ & $7.0 \pm 1.7$ & $6.3 \pm 1.9$ & $7.1 \pm 1.5$ \\
\hline RDS & $56(39.7)$ & $5(25.0)$ & $51(42.1)$ & $8(50.0)$ & $48(38.4)$ & $9(90.0)^{*}$ & 47 (35.9) & $22(61.1)^{*}$ & $34(32.4)$ \\
\hline Sepsis & $4(2.8)$ & $0(0)$ & $4(3.3)$ & $2(12.5)$ & $2(1.6)$ & $1(10.0)$ & $3(2.3)$ & $3(8.3)^{*}$ & $1(1.0)$ \\
\hline Free T4 (pmol/L) & $19.1 \pm 4.0$ & $18.9 \pm 5.0$ & $19.2 \pm 3.8$ & $19.7 \pm 3.3$ & $19.1 \pm 4.1$ & $17.0 \pm 5.1$ & $19.3 \pm 3.9$ & $17.8 \pm 5.0$ & $19.6 \pm 3.5$ \\
\hline 170-HP (pmol/L) & $358 \pm 519$ & $291 \pm 317$ & $368 \pm 545$ & $631 \pm 1268^{*}$ & $323 \pm 313$ & $363 \pm 419$ & $357 \pm 527$ & $679 \pm 912$ & $247 \pm 184$ \\
\hline $\mathrm{PIH}$ & $31(22.0)$ & $5(25.0)$ & $26(21.5)$ & $5(31.3)$ & $26(20.8)$ & $2(20)$ & $29(22.1)$ & $10(27.8)$ & $21(20.0)$ \\
\hline Maternal steroid & $122(86.5)$ & $17(85.0)$ & $105(86.8)$ & 15 (93.8) & 107 (85.6) & $10(100)$ & $112(85.5)$ & $35(97.2)^{*}$ & 87 (82.9) \\
\hline
\end{tabular}

Values are presented as mean \pm standard deviation or number (\%).

GA, gestational age; SGA, small for gestational age; GIR, glucose infusion rate; RDS, respiratory distress syndrome; 17-OHP, 17-hydroxyprogesterone; PIH, pregnancy-induced hypertension.

${ }^{*} P<0.05$ between groups. ${ }^{a)}$ Time from birth. ${ }^{b}$ Full feeding: oral intake more than $100 \mathrm{~mL} / \mathrm{kg} /$ day 
hyperglycemia. Infants who developed hypoglycemia within 24 hours had lower Apgar score than who did not. Those who developed hypoglycemia during days 2 to 7 had lower birthweight and Apgar score, and were younger than those who did not. Group with hyperglycemia during days 2 to 7 had higher proportion of SGA, and also reported higher prevalence of respiratory distress syndrome and sepsis (Table 2).

\section{Blood glucose levels}

An average of 17.5 samples per infant were done within 7 days of birth. The median blood glucose level 1 hour after birth was $3.66 \mathrm{mmol} / \mathrm{L}(66 \mathrm{mg} / \mathrm{dL})$, the lowest level recorded throughout the study period, whereas the highest measurement was $6.38 \mathrm{mmol} / \mathrm{L}(115 \mathrm{mg} / \mathrm{dL})$, obtained on day 7. The 2.5thpercentile level was lowest at $1.05 \mathrm{mmol} / \mathrm{L}(19 \mathrm{mg} / \mathrm{dL})$ at 2 hours, and peaked at $3.4 \mathrm{mmol} / \mathrm{L}(62 \mathrm{mg} / \mathrm{dL})$ on day 6 . The 97.5th-percentile blood glucose level was $6.71 \mathrm{mmol} / \mathrm{L}(120.7$ $\mathrm{mg} / \mathrm{dL})$ at 1 hour and peaked at $15.4 \mathrm{mmol} / \mathrm{L}(276.5 \mathrm{mg} / \mathrm{dL})$ at day 7 (Figs. 1,2). The 5th blood glucose levels were lowest at 2 hours after birth at $1.89 \mathrm{mmol} / \mathrm{L}(34 \mathrm{mg} / \mathrm{dL})$ (data not shown).

During the first 2 hours, 18 neonates (12.8\%) exhibited hypoglycemia, while hyperglycemia developed in just 2 neonates (1.4\%). From 6 to 24 hours, hypo- and hyperglycemia were observed in $0(0 \%)$ and 9 neonates $(6.4 \%)$, respectively. Overall, 29 (20.6\%) and 42 neonates (29.8\%) developed hypoand hyperglycemia over 7 days, respectively. Eleven infants $(7.8 \%)$ developed both hypo- and hyperglycemia, whereas 81 (57.4\%) showed neither.

\section{Blood glucose levels according to GA}

At 1 hour after birth, median blood glucose levels were lowest in infants with a GA of 30 to $<32$ weeks and highest in those with a GA $<28$ weeks ( 3.27 and $4.72 \mathrm{mmol} / \mathrm{L}$, respectively) (Fig. 1). Median blood glucose levels were lower on the first day in all GA groups. Median blood glucose levels peaked at day 7 in infants with a $\mathrm{GA}<32$ weeks and showed steady levels, ranging from 3.67 to $5.44 \mathrm{mmol} / \mathrm{L}$ ( 66 to $98 \mathrm{mg} / \mathrm{dL}$ ), in those with a GA $\geq 32$ weeks (Fig. 2).

\section{Hypo-/hyperglycemia according to GA}

During the first 24 hours, hypoglycemic episodes were most common in the GA 30 to $<32$ weeks group ( $20 \%, 3$ of 15 patients) and least common in those with a GA<28 weeks (9.5\%, 2 of 21 patients), although these intergroup differences were not statistically significant. Hyperglycemia was higher in the younger GA group $(19 \%, 6.7 \%, 5.1 \%$, and $4.5 \%$ in $\mathrm{GA}<28$, 28 to $<30,30$ to $<32$, and $\geq 32$ weeks, respectively), although not statistically significant (Table 1 ).

During days 2 to 7 , hyperglycemia occurred more frequently in the younger age groups; 16 of 21 neonates $(76.2 \%)$ with a $\mathrm{GA}<28$ weeks developed hyperglycemia, while only 6 of 66 neonates $(9.1 \%)$ with a $\mathrm{GA} \geq 32$ weeks exhibited hyperglycemia. No significant differences regarding the incidence of hypoglycemia were observed among the groups (Table 1).
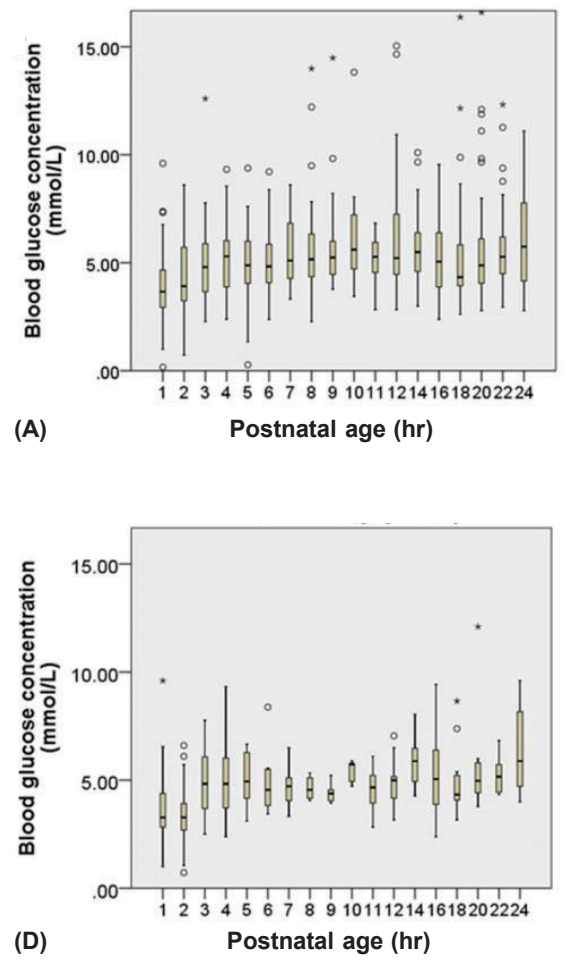
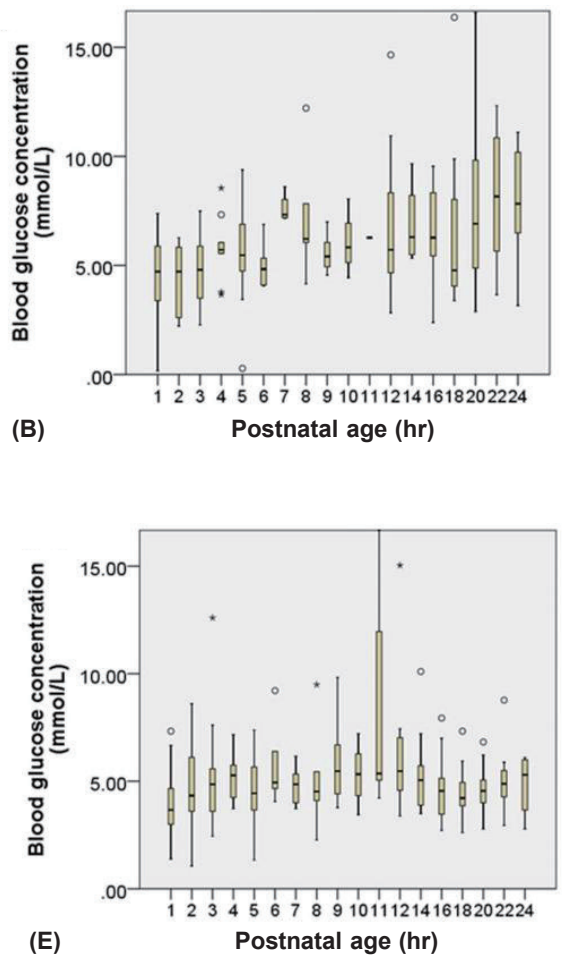

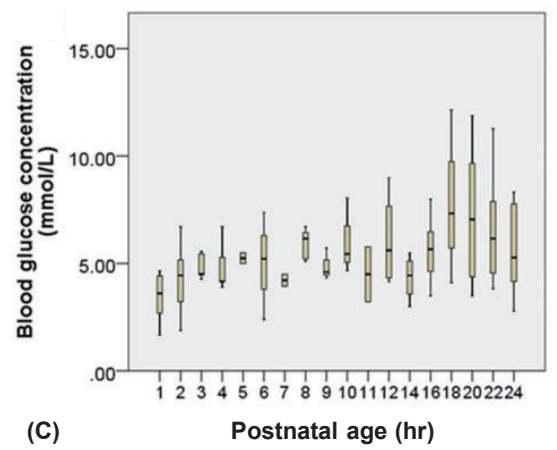

Fig. 1. Blood glucose levels within 24 hours. (A) In all the subjects; (B) subjects with gestational age $<28$ weeks; (C) 28 to $<30$ weeks; (D) 30 to $<32$ weeks; and $(E) \geq 32$ weeks. Lower and upper limit are mean \pm 2 standard deviation. Bars express inter quartile range. *Outlier. 

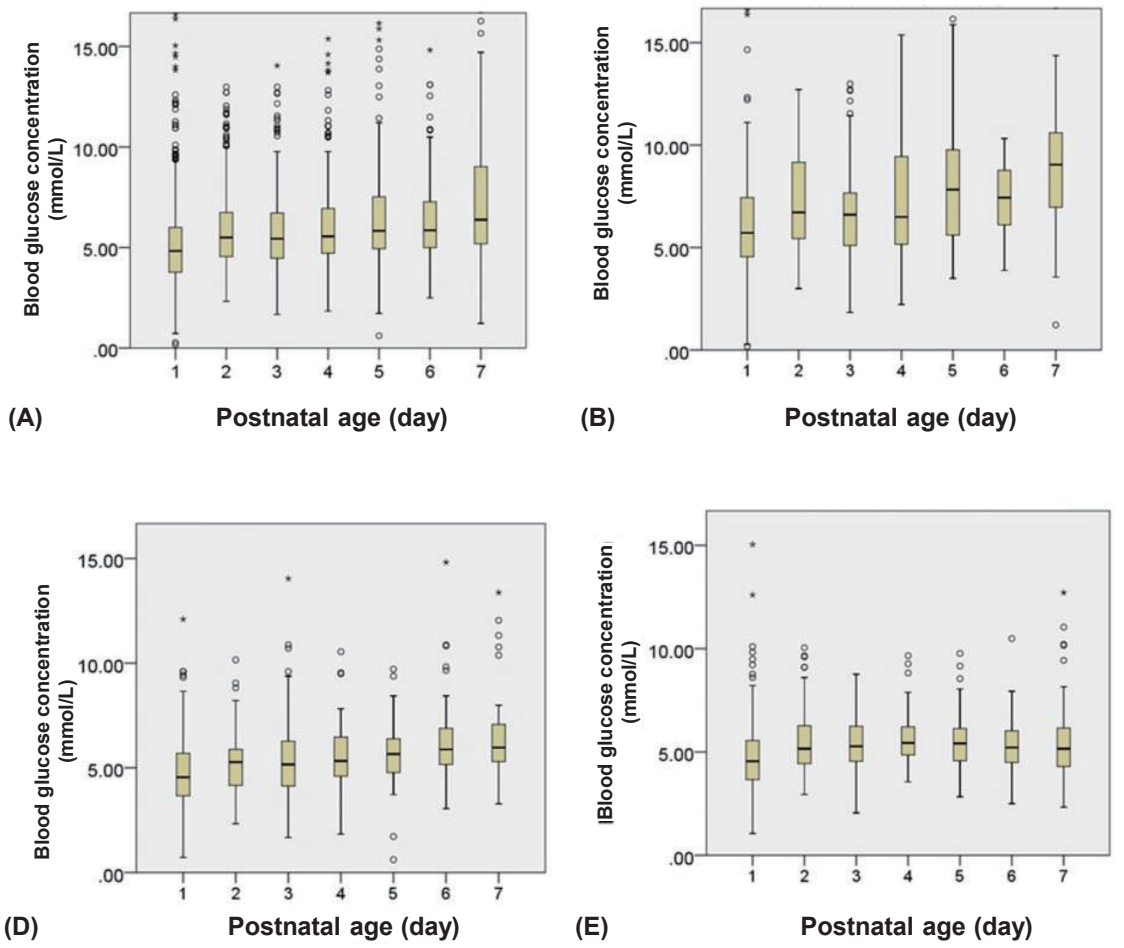

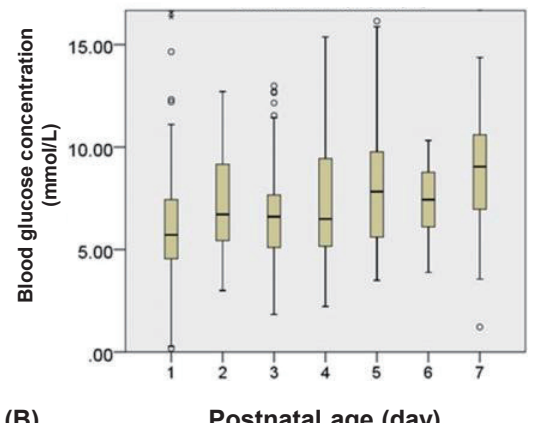

(B)

Postnatal age (day)

(C)

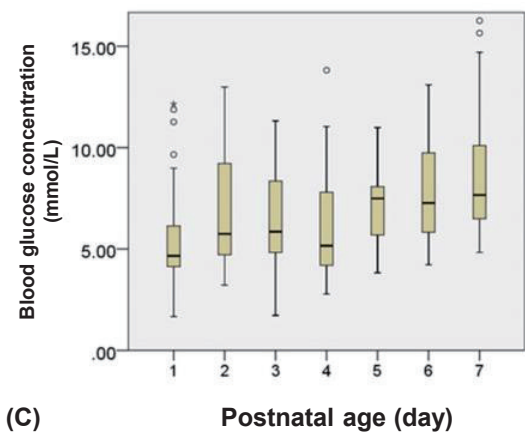

Fig. 2. Blood glucose levels over 7 days. (A) In all the subjects; (B) subjects with gestational age $<28$ weeks; (C) 28 to $<30$ weeks; (D) 30 to $<32$ weeks; and (E) $\geq 32$ weeks. Lower and upper limit are mean \pm 2 standard deviation. Bars express inter quartile range. *Outlier.

\section{Risk factors for hypoglycemia}

Univariate logistic regression analysis was performed to determine risk factors for hypoglycemia. The results showed that SGA was significant risk factors for hypoglycemia within 24 hours (OR, 2.718; 95\% CI, 1.023-7.219). Having started feeding was related with decreased hypoglycemia within 24 hours (OR, 0.294; 95\% CI, 0.112-0.775). For hypoglycemia during days 2 to 7, SGA and low 1-minute Apgar score were risk factors (Table 3).

\section{Risk factors for hyperglycemia}

In order to evaluate the risk factors for hyperglycemia, univariate logistic regression analysis was performed using the same independent variables as those used for hypoglycemia. Risk of hyperglycemia within 24 hours decreased in those who had started feeding feeding (OR, 0.162; 95\% CI, 0.040-0.662). The risk of hyperglycemia 2 to 7 days after birth increased in SGA infants and those with low 1-minute Apgar score (Table 4).

\section{Discussion}

Shortly after birth, the response of hormones regulating blood glucose levels is less sensitive because of the immaturity of cyclic adenosine monophosphate, a second messenger related to glucose metabolism. In addition, preterm neonates have a lower glycogen storage capacity than full-term neonates. Therefore, postnatal hypoglycemia is common in preterm neonates.

Hyperglycemia too is more common in preterm neonates than in full-term neonates. One of the reasons for this is a reduced ability to suppress endogenous glucose production in the body during glucose infusion. Another common mechanism responsible for hyperglycemia in preterm infants is the lack of insulin-sensitive tissues such as muscle and adipose tissue ${ }^{12)}$. In addition, condition such as sepsis and necrotising enterocolitis can induce both hepatic and peripheral insulin resistance, which lead to stress induced hyperglycemia ${ }^{13)}$. There is no consensus for definition of hypo- and hyperglycemia in neonates. In previous studies definition of hypoglycemia ranges from 1.7 to $2.6 \mathrm{mmol} / \mathrm{L}^{14)}$. For defining hyperglycemia in preterm infants, cutoff value of $150 \mathrm{mg} / \mathrm{dL}$ or $180 \mathrm{mg} / \mathrm{dL}$ is commonly used ${ }^{15,16)}$. In our study, hypo- and hyperglycemia was defined by values outside target blood glucose level used in our center.

The present study investigated blood glucose levels shortly after birth in preterm neonates, as well as associated risk factors for hypo- and hyperglycemia. The median blood glucose level was lowest 1 hour after birth, consistent with results from a study by Srinivasan et al. ${ }^{17)}$ on blood glucose levels in fullterm neonates. In that study, both the 5th- and 95th-percentile blood glucose levels were lowest from 10 to 14 hours ${ }^{18}$. However, in our study, the 5th-percentile blood glucose level was lowest at 2 hours after birth. This discrepancy is likely attributable to differences in glucose infusion as glucose was infused intravenously only when a neonate presented with hypoglycemia in Srinivasan et al. ${ }^{17)}$ 's study, whereas intravenous glucose was given to all cases in our study. In the present study, prevalence of hypoglycemia peaked on day 2 , consistent with the results obtained by Srinivasan et al. ${ }^{17}{ }^{7}$. In the first 1 hour after birth, blood glucose level was the highest in $\mathrm{GA}<28$ weeks 
group. This is explained by immaturity of beta cell enzymatic pathways and shortage of insulin sensitive tissue ${ }^{12}$.

In the present study, the incidence of hypoglycemia was higher in SGA infants than in infants with weights appropriate for GA (AGA). Concordantly, Lubchenco and Bard ${ }^{2}$ reported the incidences of hypoglycemia in preterm and full-term SGA neonates to be $67 \%$ and $25 \%$, respectively, higher than those observed in AGA infants. Increased risk of hypoglycemia in SGA infants can be explained by decreased glycogen stores, increased insulin sensitivity and higher energy requirements ${ }^{19)}$.

The incidence of hyperglycemia in the present study was $29.1 \%$. Hays et al. ${ }^{20)}$ previously reported an incidence of $60 \%$ within 7 days of birth. This difference may be accounted for by that study's inclusion of only infants with a birth weight $<1$ $\mathrm{kg}$ and a lower cutoff value of $8.33 \mathrm{mmol} / \mathrm{L}(150 \mathrm{mg} / \mathrm{dL})$ for defining hyperglycemia.

In our study, 1-minute Apgar score was associated with both hypo- and hyperglycemia. This is in accordance with previous findings that neonates with perinatal distress are prone to both hypoglycemia $^{21)}$ and hyperglycemia ${ }^{22)}$.

Both hypo- and hyperglycemia within 24 hours decreased in those who started feeding within 24 hours. On the contrary, in recent study of 203 SGA infants, feeding did not prevent hypoglycemia ${ }^{19)}$. But this study included full term infants and investigated effect of early feeding defined as feeding before
4 hours after birth. The relationship of feeding with blood glucose level is not well known in preterm infants, and further investigation is required.

The major strengths of the present study lie in its singlecenter design, standardized blood glucose level measurement method, and relatively large sample size. Furthermore, we not only investigated the incidence of hypo- and hyperglycemia but also recorded detailed temporal changes in blood glucose levels.

Nevertheless, a limitation of this study is that the effect of intravenous glucose infusion was investigated only in conjunction with oral intake and was not analyzed in detail. Furthermore, we did not continuously measure blood glucose levels; instead, blood glucose levels were measured intermittently, usually once per day from 4 days onwards. Therefore, the overall incidence of hypo- and hyperglycemia may have been underestimated when compared to the incidence observed with continuous blood glucose monitoring. However, the prevalence of hypo- and hyperglycemia at each individual time point may have been overestimated, as blood glucose levels were measured more frequently in cases where hypo- and hyperglycemia developed.

In conclusion, hypo- and hyperglycemia is common in preterm infants and careful blood glucose level monitoring is required especially in SGA infants or those with low Apgar score. Early feeding could be beneficial for prevention of hypo-

Table 3. Factors influencing hypoglycemia (univariate analysis, grouped by GA)

\begin{tabular}{|c|c|c|c|c|c|c|c|c|c|c|c|c|}
\hline \multirow{3}{*}{ Variable } & \multicolumn{6}{|c|}{ Hypoglycemia within 24 hours } & \multicolumn{6}{|c|}{ Hypoglycemia during days 2-7 } \\
\hline & \multicolumn{2}{|c|}{ All subjects $(n=141)$} & \multicolumn{2}{|c|}{$G A(w k)<32(n=75)$} & \multicolumn{2}{|c|}{$G A(w k) \geq 32(n=66)$} & \multicolumn{2}{|c|}{ All subjects $(n=141)$} & \multicolumn{2}{|c|}{$\mathrm{GA}(w k)<32(n=75)$} & \multicolumn{2}{|c|}{$G A(w k) \geq 32(n=66)$} \\
\hline & $\mathrm{OR}(95 \% \mathrm{Cl})$ & $\begin{array}{c}P_{-} \\
\text {value }\end{array}$ & $\mathrm{OR}(95 \% \mathrm{Cl})$ & $\begin{array}{c}P_{-} \\
\text {value }\end{array}$ & OR $(95 \% \mathrm{Cl})$ & $\begin{array}{c}P- \\
\text { value }\end{array}$ & $\mathrm{OR}(95 \% \mathrm{Cl})$ & $\begin{array}{c}P- \\
\text { value }\end{array}$ & OR $(95 \% \mathrm{Cl})$ & $\begin{array}{c}P_{-} \\
\text {value }\end{array}$ & OR $(95 \% \mathrm{Cl})$ & $\begin{array}{c}P_{-} \\
\text {value }\end{array}$ \\
\hline SGA & $\begin{array}{c}2.718 \\
(1.023-7.219)\end{array}$ & 0.045 & $\begin{array}{c}2.269 \\
(0.667-7.723)\end{array}$ & 0.190 & $\begin{array}{c}3.273 \\
(0.639-16.771)\end{array}$ & 0.155 & $\begin{array}{c}4.454 \\
(1.522-13.03)\end{array}$ & 0.006 & $\begin{array}{c}3.354 \\
(0.981-11.474)\end{array}$ & 0.054 & $\begin{array}{c}8.500 \\
(0.711-101.6)\end{array}$ & 0.091 \\
\hline $\begin{array}{l}\text { Apgar score } \\
(1 \mathrm{~min})\end{array}$ & $\begin{array}{c}0.941 \\
(0.746-1.187)\end{array}$ & 0.608 & $\begin{array}{c}0.959 \\
(0.707-1.299)\end{array}$ & 0.785 & $\begin{array}{c}1.078 \\
(0.660-1.761)\end{array}$ & 0.763 & $\begin{array}{c}0.756 \\
(0.583-0.980)\end{array}$ & 0.035 & $\begin{array}{c}0.824 \\
(0.598-1.135)\end{array}$ & 0.236 & $\begin{array}{c}0.854 \\
(0.464-1.573)\end{array}$ & 0.613 \\
\hline $\begin{array}{l}\text { Feeding start } \\
\text { within } 24 \text { hours }{ }^{\mathrm{a}}\end{array}$ & $\begin{array}{c}0.294 \\
(0.112-0.775)\end{array}$ & 0.013 & $\begin{array}{c}0.247 \\
(0.062-0.986)\end{array}$ & 0.048 & $\begin{array}{c}0.436 \\
(0.042-4.565)\end{array}$ & 0.489 & - & - & - & - & - & - \\
\hline $\begin{array}{l}\text { Time to full } \\
\text { feeding (day) }\end{array}$ & - & - & - & - & - & - & $\begin{array}{c}1.014 \\
(0.671-1.532)\end{array}$ & 0.947 & $\begin{array}{c}0.787 \\
(0.485-1.278)\end{array}$ & 0.333 & $\begin{array}{c}1.575 \\
(0.550-4.507)\end{array}$ & 0.397 \\
\hline
\end{tabular}

$\mathrm{GA}$, gestational age; $\mathrm{SGA}$, small for $\mathrm{GA}$; OR, odds ratio; $\mathrm{Cl}$, confidence interval.

${ }^{a)}$ Time from birth. ${ }^{\text {b) }}$ Full feeding: oral intake more than $100 \mathrm{~mL} / \mathrm{kg} /$ day.

Table 4. Factors influencing hyperglycemia (univariate analysis, grouped by GA)

\begin{tabular}{|c|c|c|c|c|c|c|c|c|c|c|c|c|}
\hline \multirow{3}{*}{ Variable } & \multicolumn{6}{|c|}{ Hyperglycemia within 24 hours } & \multicolumn{6}{|c|}{ Hyperglycemia during days $2-7$} \\
\hline & \multicolumn{2}{|c|}{ All subjects $(n=141)$} & \multicolumn{2}{|c|}{$G A(w k)<32(n=75)$} & \multicolumn{2}{|c|}{$G A(w k) \geq 32(n=66)$} & \multicolumn{2}{|c|}{ All subjects $(n=141)$} & \multicolumn{2}{|c|}{$\mathrm{GA}(\mathrm{wk})<32(\mathrm{n}=75)$} & \multicolumn{2}{|c|}{$G A(w k) \geq 32(n=66)$} \\
\hline & $\mathrm{OR}(95 \% \mathrm{Cl})$ & $\begin{array}{c}P_{-} \\
\text {value }\end{array}$ & $\begin{array}{c}\text { OR } \\
(95 \% \mathrm{Cl})\end{array}$ & $\begin{array}{c}P_{-} \\
\text {value }\end{array}$ & $\begin{array}{c}\text { OR } \\
(95 \% \mathrm{Cl})\end{array}$ & $\begin{array}{c}P_{-} \\
\text {value }\end{array}$ & $\mathrm{OR}(95 \% \mathrm{Cl})$ & $\begin{array}{c}P_{-} \\
\text {value }\end{array}$ & $\mathrm{OR}(95 \% \mathrm{Cl})$ & $\begin{array}{c}P_{-} \\
\text {value }\end{array}$ & OR $(95 \% \mathrm{Cl})$ & $\begin{array}{c}P- \\
\text { value }\end{array}$ \\
\hline SGA & $\begin{array}{c}1.980 \\
(0.526-7.450)\end{array}$ & 0.312 & $\begin{array}{c}3.439 \\
(0.703-16.83)\end{array}$ & 0.127 & $0.000(-)$ & 0.999 & $\begin{array}{c}3.200 \\
(1.419-7.214)\end{array}$ & 0.005 & $\begin{array}{c}3.500 \\
(1.257-9.742)\end{array}$ & 0.016 & $\begin{array}{c}2.000 \\
(0.327-12.24)\end{array}$ & 0.453 \\
\hline $\begin{array}{l}\text { Apgar score } \\
(1 \mathrm{~min})\end{array}$ & $\begin{array}{c}0.780 \\
(0.569-1.070)\end{array}$ & 0.124 & $\begin{array}{c}0.678 \\
(0.427-1.075)\end{array}$ & 0.098 & $\begin{array}{c}1.253 \\
(0.553-2.838)\end{array}$ & 0.589 & $\begin{array}{c}0.789 \\
(0.651-0.956)\end{array}$ & 0.016 & $\begin{array}{c}0.873 \\
(0.687-1.11)\end{array}$ & 0.267 & $\begin{array}{c}1.077 \\
(0.637-1.822)\end{array}$ & 0.782 \\
\hline $\begin{array}{l}\text { Feeding start } \\
\text { within } 24 \text { hours }\end{array}$ & $\begin{array}{c}0.162 \\
(0.040-0.662)\end{array}$ & 0.011 & $\begin{array}{c}0.148 \\
(0.017-1.297)\end{array}$ & 0.085 & $\begin{array}{c}0.136 \\
(0.010-1.835)\end{array}$ & 0.133 & - & - & - & - & - & - \\
\hline $\begin{array}{l}\text { Time to full } \\
\text { feeding (day) }\end{array}$ & - & - & - & - & - & - & $\begin{array}{c}1.308 \\
(0.977-1.751)\end{array}$ & 0.071 & $\begin{array}{c}1.234 \\
(0.877-1.736)\end{array}$ & 0.228 & $\begin{array}{c}0.543 \\
(0.204-1.443)\end{array}$ & 0.220 \\
\hline
\end{tabular}

GA, gestational age; SGA, small for GA; OR, odds ratio; $\mathrm{Cl}$, confidence interval.

${ }^{\text {a) }}$ Time from birth. ${ }^{\text {b) }}$ Full feeding: oral intake more than $100 \mathrm{~mL} / \mathrm{kg} /$ day. 
and hyperglycemia.

\section{Conflict of interest}

No potential conflict of interest relevant to this article was reported.

\section{References}

1. Kim EY. Glucose metabolism and evaluation of hypoglycemia in neonates. Korean J Pediatr 2007;50:223-9.

2. Lubchenco LO, Bard H. Incidence of hypoglycemia in newborn infants classified by birth weight and gestational age. Pediatrics 1971;47:831-8.

3. Schultz K, Soltesz G. Transient hyperinsulinism in asphyxiated newborn infants. Acta Paediatr Hung 1991;31:47-52.

4. Tam EW, Widjaja E, Blaser SI, Macgregor DL, Satodia P, Moore AM. Occipital lobe injury and cortical visual outcomes after neonatal hypoglycemia. Pediatrics 2008; 122 : 507-12.

5. Udani V, Munot P, Ursekar M, Gupta S. Neonatal hypoglycemic brain - injury a common cause of infantile onset remote symptomatic epilepsy. Indian Pediatr 2009;46:12732.

6. Caraballo RH, Sakr D, Mozzi M, Guerrero A, Adi JN, Cersosimo RO, et al. Symptomatic occipital lobe epilepsy following neonatal hypoglycemia. Pediatr Neurol 2004;31: 24-9.

7. Montassir H, Maegaki Y, Ohno K, Ogura K. Long term prognosis of symptomatic occipital lobe epilepsy secondary to neonatal hypoglycemia. Epilepsy Res 2010;88:93-9.

8. Lucas A, Morley R, Cole TJ. Adverse neurodevelopmental outcome of moderate neonatal hypoglycaemia. BMJ 1988;297:1304-8.

9. Duvanel CB, Fawer CL, Cotting J, Hohlfeld P, Matthieu JM. Long-term effects of neonatal hypoglycemia on brain growth and psychomotor development in small-forgestational-age preterm infants. J Pediatr 1999;134:492-8.

10. Stenninger E, Flink R, Eriksson B, Sahlen C. Long-term neurological dysfunction and neonatal hypoglycaemia after diabetic pregnancy. Arch Dis Child Fetal Neonatal Ed 1998;79:F174-9.

11. Kao LS, Morris BH, Lally KP, Stewart CD, Huseby V, Kennedy KA. Hyperglycemia and morbidity and mortality in extremely low birth weight infants. J Perinatol 2006;26:730-6.

12. Mitanchez D. Glucose regulation in preterm newborn infants. Horm Res 2007;68:265-71.

13. McCowen KC, Malhotra A, Bistrian BR. Stress-induced hyperglycemia. Crit Care Clin 2001;17:107-24.

14. Harris DL, Weston PJ, Harding JE. Incidence of neonatal hypoglycemia in babies identified as at risk. J Pediatr 2012;161:787-91.

15. Ogilvy-Stuart AL, Beardsall K. Management of hyperglycaemia in the preterm infant. Arch Dis Child Fetal Neonatal Ed 2010;95:F126-31.

16. Pati NK, Maheshwari R, Pati NK, Salhan RN. Transient neonatal hyperglycemia. Indian Pediatr 2001;38:898-901.

17. Srinivasan G, Pildes RS, Cattamanchi G, Voora S, Lilien LD. Plasma glucose values in normal neonates: a new look. J Pediatr 1986;109:114-7.

18. Heck LJ, Erenberg A. Serum glucose levels in term neonates during the first 48 hours of life. J Pediatr 1987;110:119-22.

19. Bragg JJ, Green R, Holzman IR. Does early enteral feeding prevent hypoglycemia in small for gestational age neonates? J Neonatal Perinatal Med 2013;6:131-5.

20. Hays SP, Smith EO, Sunehag AL. Hyperglycemia is a risk factor for early death and morbidity in extremely low birthweight infants. Pediatrics 2006;118:1811-8.

21. Saha D, Ali MA, Haque MA, Ahmed MS, Sutradhar PK, Latif T, et al. Association of hypoglycemia, hypocalcemia and hypomagnesemia in neonates with perinatal asphyxia. Mymensingh Med J 2015;24:244-50.

22. Marquez-Gonzalez H, Munoz-Ramirez MC, RamirezGarcia MA, Pineda-Frutos MF, Hernandez-Ramirez C, Villa-Romero AR, et al. Hyperglycemia as a risk factor for mortality in critically ill neonates. Rev Med Inst Mex Seguro Soc 2014;52 Suppl 2:S104-9. 